\title{
Factors Associated with the Severity of Construction Accidents: The Case of South Australia
}

\author{
Jantanee Dumrak, (University of South Australia, Australia) \\ Sherif Mostafa, (University of South Australia, Australia) \\ Imriyas Kamardeen, (University of New South Wales, Australia) \\ Raufdeen Rameezdeen, (University of South Australia, Australia)
}

\begin{abstract}
While the causes of accidents in the construction industry have been extensively studied, severity remains an underexplored area. In order to provide more evidence for the currently limited number of empirical investigations on severity, this study analysed 24,764 construction accidents reported during 2002-11 in South Australia. A conceptual model developed through literature used personal characteristics such as age, experience, gender and language background. It also employed work-related factors such as size of organization, project size and location, mechanism of accident and body location of the injury. These facilitated demonstrating why some accidents result in only a minor severity while others are fatal. Factors such as time of accident, day of the week and season were not strongly associated with accident severities. When the factors affect the severity of accidents are well understood, high risk factors can be singled out and specific preventive measures could be developed.
\end{abstract}

Keywords: Construction, Accidents, Severity, Safety, South Australia

\section{Introduction}

The construction industry by its nature is a dangerous one. It is widely recognised as having high accident rates, which result in absence from work, loss of productivity, permanent disabilities and even fatalities (Fung et al. 2009). Apart from causing human tragedies, construction accidents also delay project progress, increase costs and damage the reputation of the builder (Gangolells et al. 2010). To prevent accidents from recurring, it is crucial to establish post-investigations so that lessons learnt can be integrated into mitigation strategies (Hinze \& Wilson 2000). In that sense, a detailed, critical analysis of accidents in the construction industry is of immense importance. Previous studies on construction accidents have looked into the causes, types of injuries and their magnitudes, places of injuries and the types of occupations that are vulnerable. One of the recurring themes in most of these studies is the disproportionate ratio of fatal to non-fatal accidents in the industry. Thus, the majority of accident prevention strategies mainly looked at fatal accidents. Nevertheless, factors affecting the severity of an accident remain an understudied area compared to factors causing an accident. Though only a few studies have examined the severity, more are required to fully comprehend why some accidents are minor in outcome while others are fatal.

The aim of this study is to provide empirical evidence using a very large accident database to further our understanding of accident severity. It uses a concept model developed through a literature review to; firstly, verify conclusions made by past studies; and secondly provide some new dimensions that have not been previously considered. The study is expected to shed some light on factors associated with accident severities. When these factors are well understood, preventive measures can be designed specifically for high risk factors. 


\section{Factors Affecting the Severity of Construction Accidents}

In order to uncover factors linked to construction accidents, researchers have used accident databases. Some studies have attempted to relate personal and work characteristics such as age, ethnicity, gender, occupation and work experience to accidents. These factors could indicate a relationship between accidents, and human physical conditions and occupational qualities. They can also help identify the groups of construction workers who are highly prone to accidents. Furthermore, they allow mitigation strategies to be specifically targeted using workers' characteristics as preliminary factors. These characteristics are believed to be influential in workers' behaviours on a construction site, which could be unsafe in certain circumstances. Hinze et al. (2005) found human errors are mainly responsible for construction accidents. A number of factors were uncovered by Choudhry and Fang (2008) relating to human error.

Site conditions or work environments play an important role in construction accidents (Chi et al. 2013). Construction sites are often labelled as unsafe, dangerous or hazardous places to work (Sherratt et al. 2013). The fact that, construction activities are diverse with changing project teams and difficult-to-handle materials and equipment, could lead to human errors that are uncontrollable (Al-Humaidi \& Tan 2010). Moreover, the temporary and transitory nature of construction sites are claimed to contribute to accidents (Hallowell \& Gambatese 2009). While environmental factors such as climate, temperature, and geographical conditions could be considered as typical characteristics for a construction site (Liao \& Perng 2008), organisational factors may include characteristics referring to construction organisations and project-based procurement of works (Rozenfeld et al. 2010). The size of construction organisation was analysed by Lingard and Holmes (2001). They justified the significance of small businesses as they are the majority in Australia and on average employ less than 20 workers. Being small firms, their characteristics were often associated with poorer management skills and inadequate implementation of safety measures. Organisational and environmental factors were focused on by Ling et al. (2009) who emphasised factors relating to time, month, location, size of organisation, and type of construction. López et al. (2008) showed that time of day and day of the week are associated with accident severity. Their study led to a further investigation into other factors associated with the environment such as climatic, geographic and behavioural factors and their impact on accident severities (López et al. 2011).

Personal and work characteristics combined with the working environment are believed to influence the creation of a hazardous environment that could be triggered by different mechanisms that cause an accident (Cheng et al. 2012; Chi et al. 2013). According to Safe Work Australia (2013), the mechanism of an accident describes the action, exposure or event directly causing an injury. The mechanism of accident could lead to a further explanation on the severity as suggested by Arquillos et al. (2012). The work of Gangolells et al. (2010) showed that construction safety can be enhanced by understanding associations between safety risks (or the mechanism of injury) and construction work types. The model developed by Chi et al. (2013) places unsafe acts, unsafe working conditions and accident types at the core in order to explain three different severity levels. In addition, the part(s) of the body affected by an accident could determine the severity. The significance of studying these two factors in a coordinated manner is evident in Pinto et al. (2012), in which the mechanism of injury (so-called accident modes) and injured body segments were used in the process of developing a work accidents severity model. In a study by Jeong (1998), an analysis of the mechanisms and bodily locations of injuries were used to explain the reasons for fatalities and non-fatalities in South Korea. The study concluded that some characteristics of accident mechanisms were associated with the injured body locations. Detailed investigations by Gibbs et al. (2005) demonstrated the mechanism of injury with injured body locations could provide a large number of clues regarding occupational safety and the selection and design of tools, equipment and materials. Table 1 summarises the main factors documented in previous studies that analysed accident databases. Mechanism of

Dumrak, J et al (2013) 'Factors associated with the severity of construction accidents: The Case of South Australia', Australasian Journal of Construction Economics and Building, 13 (4) 32-49 
accident, age of victim, and type of injury were the most frequently used in these studies. Size of company, gender, type of work, occupation, and injured body location also received reasonable attention.

\begin{tabular}{|c|c|c|c|c|c|c|c|c|c|c|c|c|c|c|c|c|c|c|c|c|c|}
\hline \multirow{2}{*}{ Factor } & \multicolumn{21}{|c|}{ Previous Study } \\
\hline & 1 & 2 & 3 & 4 & 5 & 6 & 7 & 8 & 9 & 10 & 11 & 12 & 13 & 14 & 15 & 16 & 17 & 18 & 19 & 20 & 21 \\
\hline Age & & * & * & & * & * & & * & * & * & * & * & & & & * & * & * & * & * & * \\
\hline Company size & & * & * & & * & & & & & * & & * & & & & * & & * & * & & * \\
\hline $\begin{array}{l}\text { Day of the } \\
\text { week }\end{array}$ & & * & & & & * & & & & & & & & & & & & & & * & \\
\hline Education & & & & & & & & & & & & & & & & & & & * & & \\
\hline Experience & & * & * & & & & & & & * & & * & & & & & & * & * & & \\
\hline Gender & & & * & & * & & & * & & * & * & & & & & * & * & * & * & & \\
\hline Geography & & & & & & & & & * & & & & & & & * & & & * & & \\
\hline Injury location & & & & & & * & & & & & & * & * & * & & & * & & & * & * \\
\hline Mechanism & * & & * & * & * & * & * & & * & * & * & * & * & * & * & & * & * & & & * \\
\hline Occupation & & & * & & & & & & & * & & * & & & * & * & & * & & * & \\
\hline Season & & & & & & & & & * & & & & & & & * & & & * & & \\
\hline Time & & & & & & & & & * & & & * & & & & * & & * & & * & \\
\hline Type of work & * & & * & & & & * & & * & & & & * & & * & * & & * & & & \\
\hline Type of injury & * & * & & & & & * & * & & & & * & * & * & * & * & * & & & & \\
\hline $\begin{array}{l}\text { Location of } \\
\text { site }\end{array}$ & & * & & & & & & & & & & & & & & * & & * & & * & \\
\hline Weather & & & & * & & & & & & & & & & & & & & & & & * \\
\hline
\end{tabular}

Table 1 Causal factors reported in previous analyses of accident severity

Note: 1-Ale et al. 2008; 2- Arquillos et al. 2012; 3 - Cheng et al. 2012; 4- Chi et al. 2013; 5 - Chi et al. 2005; 6Frickmann et al. 2012; 7- Gurcanli \& Mungen 2009; 8- Hinze et al. 2005; 9- Huang \& Hinze 2003; 10- Im et al. 2009; 11 - Jackson \& Loomis 2002; 12 - Jeong 1998; 13- Kartam \& Bouz 1998; 14- Kines et al. 2007; 15- Larsson \& Field 2002; 16- Ling et al. 2009; 17- Lipscomb et al. 2010; 18- Lopez et al. 2008; 19- Lopez et al. 2011; 20Macedo \& Silva 2005; 21 - Salminen et al. 1992

Based on the literature, we postulate a conceptual model, as shown in Figure 1, in which personal characteristics, work environment and activity undertaken by the victim decide the level of exposure that was present at the time of an accident. The exposure when triggered by an appropriate mechanism leads to the accident which in turn causes an injury. Thus, the five factors as given in Figure 1 could be used to explain why some accidents are very mild in severity while others are fatal.

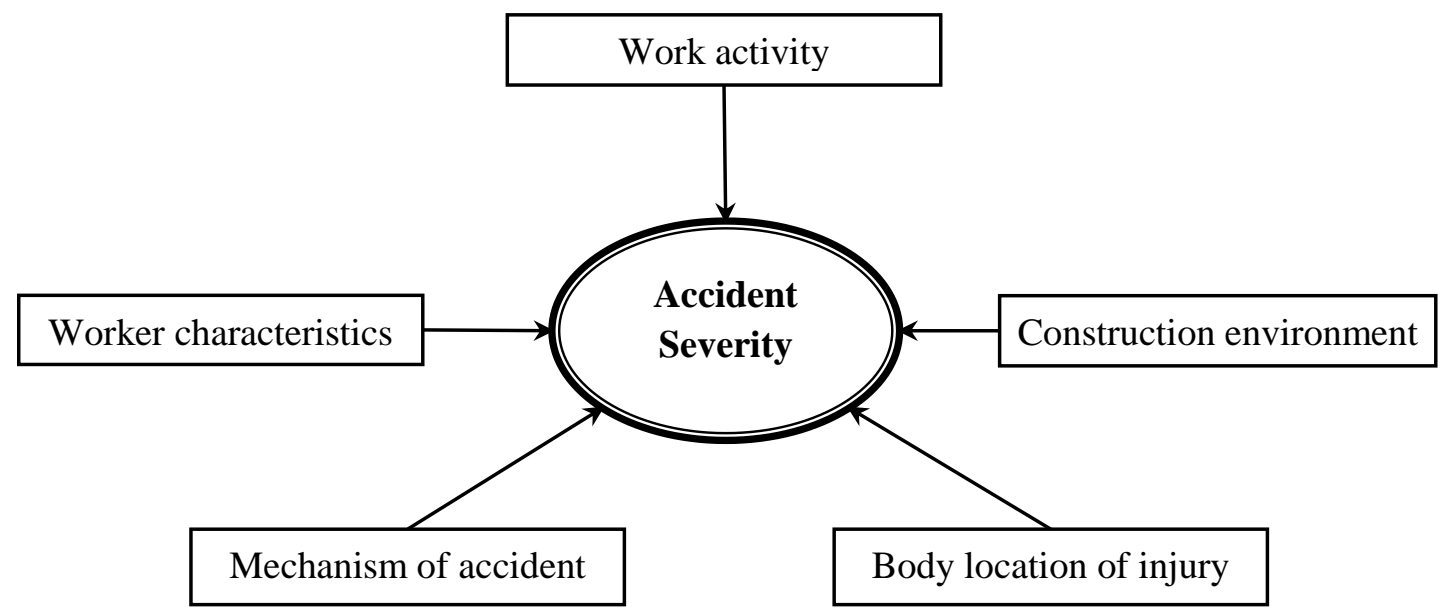

Figure 1 Factors affecting construction accident severity

Dumrak, J et al (2013) 'Factors associated with the severity of construction accidents: The Case of South Australia', Australasian Journal of Construction Economics and Building, 13 (4) 32-49 


\section{Research Method}

Data for this study came from SafeWork South Australia (SafeWork SA), which is the state government's occupational health, safety and welfare agency. It collates workers' compensation claims data obtained from WorkCover SA into a database for policy analysis. WorkCover SA is a government agency, responsible for the prevention and compensation of occupational accidents and diseases in South Australia. It is entrusted with the administration and regulation of the Workers Rehabilitation and Compensation Act 1986 and the South Australian Workers Rehabilitation and Compensation scheme. This database is made available to researchers after signing an agreement with regard to its use specifically to safeguard the confidentiality of victims. The data contained 352,360 accidents reported during 2002-11 in South Australia. Of this total, 24,764 construction accidents were extracted based on the Australian and New Zealand Standard Industrial Classification (ANZSIC) coding. The raw data was segmented into 13 sub-categories under the five main themes of the conceptual model described above. A summary of the data used for this study is given in Table 2.

There are many drawbacks in using accident databases (Larsson \& Field 2002). First, the analysis would not be detailed or rigorous enough compared to other tools such as case studies (Solis-Carcano \& Arcudia-Abad 2013; Haslam et al. 2005; Aneziris et al. 2012; Abdelhamid \& Everett 2000), questionnaire surveys (Chau et al. 2004; Tam et al. 2004; Martin et al. 2009; Rivas et al. 2011) or interviews (Haslam et al. 2005). Second, all variables associated with an accident cannot be included in the analysis due to the limited number of factors reported in a database. Third, all accidents occurring during the period under consideration would not be reported, especially the minor accidents which do not benefit from claims or fatalities for which no next-of-kin are available to report. In addition, with regard to the use of claim databases, people working in the informal sector and as sole traders or partnerships would not have an insurance policy (Larsson \& Field 2002). Thus, underreporting can create a bias in the sample that is being analysed (Dong et al. 2011). Despite these limitations, the major advantage of using accident databases is the large sample size. The present study uses 24,764 construction accidents and the large sample size provides an opportunity to use statistical tools to generalize the results. Thus, we used IBM SPSS statistical software package for data analysis.

Research hypotheses were formulated to confirm relationships between different factors of the conceptual model and accident severity. Acceptance of null hypotheses $\left(\mathrm{H}_{\mathrm{a}}\right)$ indicated no statistical association between the accident-related factor and severity. On the other hand, rejection of null hypotheses (alternative hypotheses) indicated a statistical association between the two variables. The analysis was carried out using the chi-square statistic $\left(x^{2}\right)$ for independence test. An r x c contingency table (matrix) was constructed to accommodate the chi-square test. It followed two important assumptions of the chi-square test. First, the chisquare is operated on the contingency table. It should not be performed on a repeatedmeasures design. Second, the expected frequencies must be greater than five to maintain statistical power. To overcome the second assumption's violation in the chi-square test, SPSS provides Exact Tests which are embedded in the cross-tabs dialogue box. Besides the asymptotic test of significance, the Exact method and the Monte Carlo method are included to identify the unbiased $p$-value. The Exact method is appropriate when the sample size is relatively small. On the other hand, it is suggested that for a large sample size, as in this research with 24,764 cases, the Monte Carlo method is the most appropriate. The Monte Carlo exact test is a repeated sampling method which allows large data to be computed to a $99 \%$ confidence interval for the exact $p$-value with an unbiased estimate (Mehta \& Patel 2010). 


\begin{tabular}{|c|c|c|c|}
\hline Factor & $N$ & Factor & $N$ \\
\hline Age & & Injured body location & \\
\hline Under 20 & 1367 & Trunk & 7032 \\
\hline $20-29$ & 6294 & Hand & 5054 \\
\hline $30-39$ & 6047 & Arm & 1567 \\
\hline $40-49$ & 5902 & Foot & 1655 \\
\hline $50-59$ & 3931 & Leg & 2956 \\
\hline Over 60 & 1223 & Head & 1680 \\
\hline Gender & & Eye & 1894 \\
\hline Male & 24063 & Neck & 974 \\
\hline Female & 698 & Internal organs & 357 \\
\hline Occupation & & Multiple locations & 661 \\
\hline Supervisor & 3582 & Others & 934 \\
\hline Admin officer & 524 & Project size & \\
\hline Carpenter & 1606 & Small & 9752 \\
\hline Electrician & 2428 & Medium & 11950 \\
\hline Glazier & 14 & Large & 2978 \\
\hline Landscape gardener & 828 & Organisation size & \\
\hline Mason & 1283 & Small & 9192 \\
\hline Mechanic & 1550 & Medium & 10419 \\
\hline Painter \& decorator & 629 & Large & 5069 \\
\hline Plant operator & 2852 & Time & \\
\hline Plasterer and tiler & 615 & 00.00-01.59 & 106 \\
\hline Plumber & 2349 & 02.00-03.59 & 137 \\
\hline Roof slater \& tiler & 183 & 04.00-05.59 & 98 \\
\hline Steel worker & 843 & 06.00-07.59 & 1221 \\
\hline Welder & 717 & 08.00-09.59 & 4223 \\
\hline Unskilled labourer & 2655 & $10.00-11.59$ & 5429 \\
\hline Others & 2096 & $12.00-13.59$ & 3258 \\
\hline Type of construction & & $14.00-15.59$ & 3797 \\
\hline Building & 3993 & $16.00-17.59$ & 1201 \\
\hline Heavy and civil engineering & 5778 & $18.00-19.59$ & 250 \\
\hline General construction & 2114 & 20.00-21.59 & 128 \\
\hline Construction services & 12792 & 22-00.23.59 & 91 \\
\hline Native Language & & Worksite location & \\
\hline English & 24397 & Adelaide CBD & 1002 \\
\hline Non-English & 309 & Adelaide inner suburbs & 14436 \\
\hline Experience & & Adelaide outer suburbs & 3488 \\
\hline Experienced & 18410 & Regional SA & 4540 \\
\hline New & 6354 & Season & \\
\hline Mechanism of accident & & Summer & 5855 \\
\hline Falls & 4852 & Autumn & 6364 \\
\hline Struck by & 7339 & Winter & 6299 \\
\hline Caught in/between & 752 & Spring & 6246 \\
\hline $\begin{array}{l}\text { Lifting carrying and over } \\
\text { exertion }\end{array}$ & 7888 & Weekday & \\
\hline Exposed to harmful substance & 1517 & Monday & 4838 \\
\hline Electric shock & 234 & Tuesday & 4978 \\
\hline Equipment/vehicle & 499 & Wednesday & 4738 \\
\hline \multirow{4}{*}{ Others } & 1683 & Thursday & 4468 \\
\hline & & Friday & 3962 \\
\hline & & Saturday & 1211 \\
\hline & & Sunday & 569 \\
\hline
\end{tabular}

Table 2 Summary of data representing the period 2002-2011 ( $N=24,764)$

Dumrak, J et al (2013) 'Factors associated with the severity of construction accidents: The Case of South Australia', Australasian Journal of Construction Economics and Building, 13 (4) 32-49 


\section{Defining Accident Severity}

While accident severity is an understudied area compared to accident causation (see Manu et al. (2012) for a review of accident causation in construction), past researchers have used varying scales to measure 'severity'. A classic categorisation is between fatality and nonfatality (Jeong 1998; Safe Work Australia 2013; Salminen et al. 1992; Workplace Health and Safety Queensland 2012). The work of Chi et al. (2013) classifies severity into 3 types, these being fatality, hospitalised and non-hospitalised injuries. Using a similar philosophy, Aneziris et al. (2012) classified severity into lethal injuries, non-lethal permanent injuries, and recoverable injuries. More elements have become available for the severity analyses such as work days lost, temporary and permanent injury, and categorisations such as minor or light, medium, severe or serious, and very serious (Ale et al. 2008; López et al. 2011; López et al. 2008; Ling et al. 2009; Arquillos et al. 2012; Rozenfeld et al. 2010). Some studies applied a combination of severity categories developed previously by other researchers (Salminen 2004). Other studies developed severity assessment using mathematical formulations such as fuzzification process, Monte Carlo simulation and Bayesian Statistics (Pinto et al. 2012; Martin et al. 2009). Some studies employed standard guidelines of accident severity classified by health and safety authorities or medical authorities (López et al. 2008; Ling et al. 2009). In this study, the severity of construction accidents is divided into six categories based on a combination of number of lost days and whether the victim was hospitalised for treatment:

- Minor - Incidents with no lost days or hospitalisation

- Moderate - Incidents with no lost days but hospitalisation

- Serious - Incidents with 1-3 lost days

- Severe - Incidents with 4-10 lost days

- Critical - Incidents with more than 10 lost days

- Fatal - Incidents with un-survivable conditions

\section{Results and Discussion}

The findings of the analyses are discussed below under different sections as postulated in the conceptual model in Figure 1.

\section{Worker Characteristics}

The results in Table 3 show that an increase in age is directly linked to the degree of accident severity. It shows that the majority of minor to moderate injuries are suffered by workers aged between 20 to 29 years (26.2\% and 37.5\% respectively). They are underrepresented among other levels of severities. As the age increased, the proportion of serious, severe and critical injuries tended to increase. The highest proportions of serious, severe and critical injuries occur in the 40-49 age group (around 30\%). The highest proportion of fatal accidents occurs in the 50-59 age group and this cohort is overrepresented among fatalities (almost 35\%). The results confirm that the age of construction workers was significantly associated with injury severity $\left(x^{2}=319.227 ;\right.$ d.f. $\left.=25 ; p<0.001\right)$. The relationship between the age of construction workers and injury severity has been suggested in many studies as shown in Table 1. A direct relationship, i.e. severity increase with age, was formed between these two variables (Arquillos et al. 2012; Lopez et al. 2008; Salminen 2004). Li and Poon (2009) revealed that the majority of serious injuries occur in the 47-56 age group. Cheng et al. (2012) and Jackson and Loomis (2002) found that workers older than 55 constitute the majority of fatal accidents, while Arquillos et al. (2012) concluded that workers more than 60 years old had fatal accidents. According to Frickmann et al. (2012) older workers suffered few accidents but they tended to be more severe. The present study confirms the above observations and clearly shows that older workers are prone to fatal accidents. 
In order to explore the impact of experience on accident severity, workers who had less than one year of experience at the time of accident were categorised as 'new' workers. Interestingly, the new workers who suffered accidents were highly under-represented in serious and severe levels ( $1.1 \%$ and $5.3 \%$ respectively). This clearly shows that they are less prone to moderate injuries. The result shows an association between the level of experience and severity $\left(x^{2}=110.785 ;\right.$ d.f. $\left.=5 ; p<0.001\right)$. According to Poon et al. (2002), accidents happened at a lower rate for workers with less than 1 year and more than 11 years of experience and most accidents involved persons with 1 to 10 years of work experience. Arquillos et al. (2012) show that workers who had less than one month of service in the company, and those who between 5-10 years of service are susceptible to accidents; the former due to lack of experience and the latter due to misjudgement of hazards. Lopez et al. (2008) contend that workers with less than ten days and between 10-30 years of experience are at higher risk of accidents. Rameezdeen and Ratnasabapathy (2007) confirm this phenomenon and conclude that workers who are experienced neglect hazards very often due to self-confidence that 'it won't happen to me'. Cheng et al. (2012) and Im et al. (2009) also confirm that workers with less than one month's experience are highly prone to accidents. The present study shows that not only does the severity of accidents among new workers vary, but these workers are under-represented among moderate injury consequences. A study by Teo et al. (2005) found training to be an effective way of preventing accidents, especially for those who only recently joined the construction industry.

According to the 2011 Census, females comprise 13\% of construction workers in South Australia (Australian Bureau of Statistics 2013). Though only a few females have met with accidents $(2.82 \%)$, their representation is relatively higher in serious, severe and critical levels as shown in Table $3(13.8 \%, 7.1 \%$ and $3.5 \%$ respectively). Interestingly, none of the female workers had a fatal accident during this period. The data analysis confirmed an association between gender and injury severity $\left(x^{2}=104.640 ;\right.$ d.f. $\left.=5 ; p<0.001\right)$. Many past studies have shown that female workers are under-represented among accidents in general and those with fatal and severe consequences (Cheng et al. 2012; Lopez et al. 2008; Hinze et al. 2005). While the present study confirms the above findings, a relatively high percentage of critical injuries at $13.8 \%$ and an almost negligible minor and moderate injury record $(2.7 \%$ and $1 \%$ respectively) suggest that the injuries to female workers are of moderate consequence. According to Hinze et al. (2005), the difference in severity is considered to be a reflection of the differences in occupations (trades) between men and women.

\begin{tabular}{|c|c|c|c|c|c|c|c|}
\hline \multirow{2}{*}{ Factor } & \multirow{2}{*}{$\begin{array}{c}\text { Category (\% of total } \\
\text { accidents) }\end{array}$} & \multicolumn{6}{|c|}{$\%$ of accidents within severity level } \\
\hline & & Minor & Moderate & Serious & Severe & Critical & Fatal \\
\hline \multirow{6}{*}{$\begin{array}{l}\text { Age } \\
\begin{array}{l}\left(N=24764 ; x^{2}=\right. \\
319.23 ; \text { d.f. }=25 ; \\
p<0.001)\end{array}\end{array}$} & Under 20 (5.5\%) & 5.8 & 10.2 & 3.7 & 0.6 & 2.2 & 5.0 \\
\hline & $20-29(25.4 \%)$ & 26.2 & 37.5 & 12.7 & 14.2 & 16.3 & 10.0 \\
\hline & $30-39(24.4 \%)$ & 24.5 & 18.4 & 19.6 & 19.5 & 25.9 & 17.5 \\
\hline & $40-49(23.8)$ & 23.4 & 16.7 & 31.7 & 32.5 & 29.1 & 20.0 \\
\hline & $50-59(15.9 \%)$ & 15.3 & 12.6 & 27.5 & 24.3 & 21.3 & 35.0 \\
\hline & Over $60(4.9 \%)$ & 4.9 & 4.6 & 4.8 & 8.9 & 5.3 & 12.5 \\
\hline \multirow{2}{*}{$\begin{array}{l}\text { Experience } \\
\left(\mathrm{N}=24764 ; \mathrm{x}^{2}=\right. \\
110.79 ; \text { d.f. }=5 \\
p<0.001)\end{array}$} & Experienced (74.3\%) & 74.3 & 71.2 & 98.9 & 94.7 & 71.1 & 82.5 \\
\hline & New $(25.7 \%)$ & 25.7 & 28.8 & 1.1 & 5.3 & 28.9 & 17.5 \\
\hline \multirow{2}{*}{$\begin{array}{l}\text { Gender } \\
(N=24761 ; \\
X^{2}=104.64 ; \text { d.f. }=5 ; \\
p<0.001)\end{array}$} & Male $(97.18 \%)$ & 97.3 & 99.0 & 86.2 & 92.9 & 96.5 & 100 \\
\hline & Female (2.82\%) & 2.7 & 1.0 & 13.8 & 7.1 & 3.5 & 0.0 \\
\hline \multirow{2}{*}{$\begin{array}{l}\text { Native Language } \\
\left(\mathrm{N}=24764 ; \mathrm{x}^{2}=\right. \\
31.65 ; \text { d.f. }=5 \\
p<0.001)\end{array}$} & English (98.7\%) & 98.8 & 99.3 & 99.5 & 100.0 & 97.4 & 100 \\
\hline & Non-English (1.3\%) & 1.2 & 0.7 & 0.5 & 0.0 & 2.6 & 0.0 \\
\hline
\end{tabular}

Table 3 Worker characteristics and accident severity

Dumrak, J et al (2013) 'Factors associated with the severity of construction accidents: The Case of South Australia', Australasian Journal of Construction Economics and Building, 13 (4) 32-49 
A study on young Latino workers in the US by O'Connor et al. (2005) discovered that language barriers were contributors to the Latinos' high accident and fatality rates. According to Menzel and Gutierrez (2010), language and communication were regarded as factors contributing to risks of workplace injuries. In their study, construction workers with poor English skills were prone to risks because they were unable to understand safety training and written safety instructions. The present study also confirms that non-native English speakers were highly represented among critical accidents. The percentage of non-native speakers who are critically injured is $2.6 \%$ which is twice as large as their overall representation among accidents (1.3\%). Interestingly, they are not documented in fatalities and severe injuries. Despite a very small proportion of non-English speaking workers among accident victims, language was statistically associated with accident severity $\left(x^{2}=31.645\right.$; d.f. $=5 ; p<0.001)$.

\section{Work Environment}

While company size has been studied extensively in the past as seen in Table 1, project size has not been considered to be related with accidents. In the present study, however, both the organisation size and the project size were categorised into: small, with less than 20 employees; medium, with between 21 and 200 employees; and large, with more than 200 employees. Statistical analysis indicated a significant association between the organisation size and severity $\left(X^{2}=1234.215 ;\right.$ d.f. $\left.=10 ; p<0.001\right)$. As shown in Table 4 , the representation of small companies among fatal (55\%) and critical (48\%) accidents was disproportionately high. Past studies have shown that organisation size does influence the risk exposure of workers (McVittie et al. 1997). Workers in small organisations experienced a greater severity of injuries in accidents (Lopez et al. 2008; Cheng et al. 2010; Fabiano et al. 2004). Chi et al. (2005) identified that inexperienced workers and those working for smaller companies were found to be at greater risks of fatal falls. However, the findings of Arquillos et al. (2012) were the opposite. They found larger companies had more fatal accidents than smaller companies. Im et al. (2009) demonstrated that workers of larger construction companies are prone to more accidents than those in other industries. The present study confirms the former argument that workers in small companies are vulnerable to fatal injuries.

It was believed that the larger the project size, the more efforts were needed to protect the people on site (Ankrah et al. 2009). Contrary to this assertion, results of the present study as reported in Table 4 indicate that small projects had a higher proportion of fatal (58\%) and critical (48\%) injuries. The statistical analysis confirmed an association between project size and injury severity $\left(x^{2}=977.106\right.$; d.f. $\left.=10 ; p<0.001\right)$. A review by Atkinson and Westall (2010) showed in two out of three studies that smaller projects had a higher accident frequency rate (AFR). Similarly, Cheng et al. (2012) found small private projects had a large number of accidents compared to bigger projects. On the other hand, large public projects were found to have more accidents than smaller projects. Smaller private projects do not take safety very seriously as the client is not in a position to fund safety measures. Large public projects tend to be mainly infrastructure projects which are very complex and as a result safety issues are very common. The results of the present study confirm the opinion that smaller projects are more vulnerable than medium and large projects in terms of accident severity. The observations are very similar to the issue of organisation size discussed earlier. Thus taken together, employees belonging to small companies and working for small projects were over-represented among fatal and critical accidents, while those who are from large companies and large projects faced disproportionately high serious and severe accidents. Employees of medium-sized companies and working for mediumsized projects were found to be relatively safe.

With regard to the location of site, it was asked whether location has an impact on injury severity. The hypothesis was that if the site is located in a congested high density area, more effort was needed to protect workers. A study by Ling et al. (2009) showed that high 
rise construction projects in the $\mathrm{CBD}$ contained a higher risk of fatal accidents. In the present study the post code of the site location was used: 5000 as Adelaide CBD; 5001-5100 as inner suburbs of Adelaide; 5101-5200 as outer suburbs; and above 5200 as regional South Australia. The result shows an association between the worksite location and severity $\left(x^{2}=\right.$ 155.897 ; d.f. $=15 ; p<0.001)$. A comparatively high fatality could be observed in sites located in the CBD, which is almost double (10\%) the proportion of all accidents happening in CBD sites. This supports the findings of Ling et al. (2009). However, to the contrary, projects in regional SA and the outer suburbs were more prone to fatal accidents than those occurring in the inner suburbs.

\begin{tabular}{|c|c|c|c|c|c|c|c|}
\hline \multirow{2}{*}{ Factor } & \multirow{2}{*}{$\begin{array}{l}\text { Category (\% of total } \\
\text { accidents) }\end{array}$} & \multicolumn{6}{|c|}{$\%$ of accidents within severity level } \\
\hline & & Minor & Moderate & Serious & Severe & Critical & Fatal \\
\hline \multirow{3}{*}{$\begin{array}{l}\text { Organisational } \\
\text { size } \\
\left(\mathrm{N}=24,680 ; \mathrm{x}^{2}=\right. \\
1234.22 ; \text { d.f. }=10 \\
p<0.001)\end{array}$} & Small (37.2\%) & 36.6 & 51.5 & 1.6 & 11.2 & 47.8 & 55.0 \\
\hline & Medium (42.2\%) & 43.7 & 41.0 & 2.1 & 7.1 & 32.4 & 30.0 \\
\hline & Large $(20.5 \%)$ & 19.7 & 7.5 & 96.3 & 81.7 & 19.8 & 15.0 \\
\hline \multirow{3}{*}{$\begin{array}{l}\text { Project size } \\
\left(\mathrm{N}=24,680 ; x^{2}=\right. \\
977.11 ; \text { d.f. }=10 \\
p<0.001)\end{array}$} & Small (39.5\%) & 38.8 & 52.4 & 7.9 & 19.5 & 49.8 & 57.5 \\
\hline & Medium (48.4\%) & 49.8 & 41.7 & 25.4 & 26.0 & 37.8 & 37.5 \\
\hline & Large $(12.1 \%)$ & 11.4 & 5.8 & 66.7 & 54.4 & 12.4 & 5.0 \\
\hline \multirow{4}{*}{$\begin{array}{l}\text { Worksite location } \\
\left(\mathrm{N}=23,466 ; x^{2}=\right. \\
155.90 ; \text { d.f. }=15 \\
p<0.001)\end{array}$} & Adelaide CBD (4.3\%) & 4.2 & 2.0 & 4.5 & 4.5 & 5.8 & 10.0 \\
\hline & $\begin{array}{l}\text { Adelaide inner suburbs } \\
(61.5 \%)\end{array}$ & 62.5 & 47.8 & 60.0 & 53.6 & 53.7 & 37.5 \\
\hline & $\begin{array}{l}\text { Adelaide outer suburbs } \\
(14.9 \%)\end{array}$ & 14.5 & 21.8 & 3.6 & 6.4 & 18.6 & 22.5 \\
\hline & Regional SA (19.3\%) & 18.8 & 28.5 & 31.8 & 35.5 & 22.0 & 30.0 \\
\hline \multirow{12}{*}{$\begin{array}{l}\text { Time } \\
\left(\begin{array}{l}N=19,939 ; \\
x^{2}=98.736, \text { d.f. }=55 \\
p<0.005)\end{array}\right.\end{array}$} & 00.00-01.59 (0.5\%) & 0.5 & 0.8 & 0.6 & 0.0 & 1.0 & 3.6 \\
\hline & 02.00-03.59 (0.7\%) & 0.7 & 0.5 & 2.2 & 1.3 & 0.8 & 0.0 \\
\hline & $04.00-05.59(0.5 \%)$ & 0.5 & 0.8 & 1.1 & 0.6 & 0.3 & 3.6 \\
\hline & $06.00-07.59(6.1 \%)$ & 6.1 & 5.6 & 8.9 & 7.8 & 6.0 & 3.6 \\
\hline & 08.00-09.59 (21.2\%) & 21.1 & 24.7 & 25.6 & 26.0 & 20.0 & 7.1 \\
\hline & $10.00-11.59(27.2 \%)$ & 27.5 & 23.6 & 23.9 & 31.2 & 25.1 & 21.4 \\
\hline & $12.00-13.59(16.3 \%)$ & 16.2 & 15.8 & 13.9 & 7.1 & 19.2 & 14.3 \\
\hline & $14.00-15.59(19.0 \%)$ & 19.2 & 20.9 & 14.4 & 16.9 & 17.6 & 35.7 \\
\hline & $16.00-17.59(6.0 \%)$ & 5.9 & 5.4 & 8.9 & 5.2 & 7.1 & 3.6 \\
\hline & $18.00-19.59(1.3 \%)$ & 1.2 & 0.5 & 0.0 & 2.6 & 1.5 & 7.1 \\
\hline & $20.00-21.59(0.6 \%)$ & 0.6 & 1.1 & 0.6 & 0.6 & 0.8 & 0.0 \\
\hline & $22-00.23 .59(0.5 \%)$ & 0.4 & 0.0 & 0.0 & 0.0 & 0.0 & 0.0 \\
\hline \multirow{4}{*}{$\begin{array}{l}\text { Season } \\
\begin{array}{l}\left(\mathrm{N}=24,764 ; x^{2}=23.39 ;\right. \\
\text { d.f. }=15 ; p=0.076)\end{array}\end{array}$} & Summer (23.6\%) & 23.7 & 21.8 & 29.1 & 29.6 & 21.7 & 27.5 \\
\hline & Autumn (25.7\%) & 25.8 & 28.8 & 24.3 & 19.5 & 24.6 & 37.5 \\
\hline & Winter (25.4\%) & 25.3 & 24.5 & 22.2 & 26.6 & 27.5 & 15.0 \\
\hline & Spring $(25.2 \%)$ & 25.2 & 24.9 & 24.3 & 24.3 & 26.2 & 20.0 \\
\hline \multirow{7}{*}{$\begin{array}{l}\text { Weekday } \\
\left(\mathrm{N}=24,764 ; x^{2}=\right. \\
40.98 ; \text { d.f. }=30 ; p= \\
0.087)\end{array}$} & Monday (19.5\%) & 19.6 & 22.8 & 16.4 & 18.9 & 17.9 & 20.0 \\
\hline & Tuesday (20.1\%) & 20.2 & 18.4 & 18.0 & 21.3 & 19.3 & 22.5 \\
\hline & Wednesday (19.1\%) & 19.1 & 18.9 & 23.8 & 16.6 & 19.7 & 20.0 \\
\hline & Thursday (18.0\%) & 18.0 & 19.4 & 21.7 & 18.9 & 17.4 & 15.0 \\
\hline & Friday $(16.0 \%)$ & 15.9 & 16.0 & 12.2 & 13.6 & 17.4 & 10.0 \\
\hline & Saturday $(4.9 \%)$ & 4.9 & 3.1 & 3.2 & 6.5 & 5.1 & 7.5 \\
\hline & Sunday (2.3\%) & 2.2 & 1.5 & 4.8 & 4.1 & 3.1 & 5.0 \\
\hline
\end{tabular}

Table 4 Work environment and injury severity

Dumrak, J et al (2013) 'Factors associated with the severity of construction accidents: The Case of South Australia', Australasian Journal of Construction Economics and Building, 13 (4) 32-49 
Past research has shown that the time of accident has an impact on the severity (Loudoun 2010). Kines (2002) revealed that fatalities were associated with the period just after lunch. Lopez et al. (2011) detected a similar phenomenon in Spain and called it the lunch time effect'. In Singapore, most fatal accidents occurred around 09.30-11.30 am and 02.30-03.00 pm (Ling et al. 2009). A similar result for the USA was reported by Huang and Hinze (2003) where most construction accidents occur between 10:00-11:00 in the morning and 13:0014:00 in the afternoon. The present study confirms the above observations and finds a disproportionally high fatality during $2-4 \mathrm{pm}$, which is almost $35 \%$. While a relatively large number of accidents occur during 8-10 am, the proportion of fatalities is very low (7\%). Similarly, during 10-12 noon, the proportion of fatalities is slightly lower than the overall injuries $(21 \%$ against $27 \%)$. Despite confirming some past observations, the association between time of accident and severity in the present study is relatively weak $(X 2=98.736$; d.f. $=55 ; p<0.005)$.

Similar to the above results, the study could not establish an association between the day of the week and injury severity $(x 2=40.975$; d.f. $=30 ; p=0.087)$ as well as climatic season and severity $(x 2=23.386$; d.f. $=15 ; p=0.076)$. However, past studies have shown these two variables have a positive relationship with accidents. For example, Arquillos et al. (2012) used seasons to differentiate the climate zone characteristics of Spain. The study found that climate conditions influenced the severity rates. Huang and Hinze (2003) indicated a higher accident rate in summer compared to winter. Chi et al. (2013) showed weather conditions had a statistically significant relationship with accident types. Nevertheless, the study failed to show a relationship between weather and injury severity. According to the findings of Ling et al. (2009), fatalities in Singapore's construction industry increased just before the rainy season began due to the rush to complete work. Day of the week was reported by López et al. (2008) as a factor associated with injury severity. The study claimed the number of accidents fell as the week progressed. Arquilos et al. (2012) showed Monday had a disproportionately high accident rate and called it the 'Monday Effect'. Liao and Perng (2008) revealed that the majority of fatalities in building construction occurred during the morning (7.00 to 11.00) of a rainy Monday or Tuesday in Taiwan.

\section{Activity at the Time of Accident}

The work activity carried out by the victim at the time of accident was considered to be instrumental in deciding the severity. Accordingly, the type of construction and the occupation of victim were included to represent this variable. According to Australia's 2011 Census, out of 53,576 workers, $30.5 \%$ were involved in building works, $7.5 \%$ heavy and civil engineering works, $2.3 \%$ general construction, and $59.6 \%$ in construction services (Australian Bureau of Statistics 2013). The results of the present study show that workers in the building sub-sector were over-represented in fatalities (30\%) while those in the heavy and civil engineering sub-sector mainly accounted for serious and severe accidents $(80 \%$ and $68 \%$ respectively). The analysis showed a significant association between the type of construction and the level of injury severity $(x 2=606.756$; d.f. $=20 ; p<0.001)$. According to Cheng et al. (2012), accidents are more common in building construction compared to the other sub-sectors. Huang and Hinze (2003) found that falls are very common in commercial and single residential building projects. The results of the present study confirm the above observations and show that severity of accidents among workers in the building sub-sector is comparatively higher than in the other sectors.

With regard to occupation, seventeen major categories as listed in Table 5 were included. Carpenters were found to be over-represented in moderate accidents; unskilled workers in serious and severe accidents; mechanics and plant operators in fatal accidents. Fatalities among mechanics and plant operators $(12.5 \%$ and $25 \%$ ) were almost double that of their representation in overall injuries $(6.3 \%$ and $11.5 \%$ respectively). Statistical analyses confirmed a significant association between the occupation and the level of injury severity $(x 2=610.699 ;$ d.f. $=80 ; p<0.001)$. Jackson and Loomis (2002) contended that unskilled 
workers, truck drivers, operators and electricians were over-represented in fatalities in the USA. As expected, roofers were the majority among falls in the USA (Huang and Hinze 2003). Im et al. (2009) found that painters, scaffolders and plasterers represented the majority of fall victims. Larsson and Field (2002) argued that fall risk appears to vary according to the occupation concerned. While the present study confirms the observations of Jackson and Loomis (2002) for truck drivers, operators and electricians being highly vulnerable to fatal accidents, the results do not support the position of unskilled workers. According to the results, unskilled workers were over-represented among serious (30\%) and severe (23\%) injuries but not among fatalities (5\%).

\begin{tabular}{|c|c|c|c|c|c|c|c|}
\hline \multirow{2}{*}{ Factor } & \multirow{2}{*}{$\begin{array}{c}\text { Category (\% of total } \\
\text { accidents) }\end{array}$} & \multicolumn{6}{|c|}{$\%$ of accidents within severity level } \\
\hline & & Minor & Moderate & Serious & Severe & Critical & Fatal \\
\hline \multirow{4}{*}{$\begin{array}{l}\text { Type of } \\
\text { construction } \\
(\mathrm{N}=24,677 ; \\
\mathrm{X}^{2}=606.76 ; \\
\text { d.f. }=20 ; p< \\
0.001)\end{array}$} & Building (16.25) & 16.5 & 17.7 & 8.5 & 13.6 & 13.0 & 30.0 \\
\hline & Heavy and civil $(23.4 \%)$ & 22.5 & 17.7 & 79.4 & 68.0 & 26.2 & 25.0 \\
\hline & General const. (8.6\%) & 8.4 & 6.6 & 1.1 & 2.4 & 11.9 & 2.5 \\
\hline & Const. services (51.8\%) & 52.6 & 58.0 & 11.1 & 16.0 & 48.8 & 42.5 \\
\hline \multirow{17}{*}{$\begin{array}{l}\text { Occupation } \\
\left(\mathrm{N}=24,754 ; \mathrm{x}^{2}=\right. \\
610.70 ; \text { d.f. }=80 \\
p<0.001)\end{array}$} & Supervisor (14.5\%) & 14.3 & 11.6 & 12.7 & 14.8 & 16.8 & 12.5 \\
\hline & Admin officer (2.1\%) & 1.9 & 1.5 & 13.8 & 5.9 & 3.1 & 0.0 \\
\hline & Carpenter (6.5\%) & 6.5 & 13.8 & 4.8 & 2.4 & 5.8 & 5.0 \\
\hline & Electrician (9.8\%) & 10.2 & 11.4 & 3.7 & 5.3 & 5.9 & 12.5 \\
\hline & Glazier $(0.1 \%)$ & 0.05 & 0.0 & 0.5 & 0.6 & 0.1 & 0.0 \\
\hline & Landscape gardener (3.3\%) & 3.4 & 4.4 & 0.0 & 0.6 & 2.9 & 0.0 \\
\hline & Mason $(5.2 \%)$ & 5.0 & 6.3 & 0.0 & 0.0 & 7.6 & 5.0 \\
\hline & Mechanic (6.3\%) & 6.5 & 5.6 & 3.7 & 4.7 & 4.0 & 12.5 \\
\hline & Painter \& decorator (2.5\%) & 2.5 & 1.5 & 1.6 & 1.8 & 3.9 & 2.5 \\
\hline & Plant operator (11.5\%) & 11.2 & 11.4 & 15.9 & 17.8 & 14.5 & 25.0 \\
\hline & Plasterer and tiler (2.5\%) & 2.4 & 1.2 & 0.5 & 0.6 & 3.8 & 5.0 \\
\hline & Plumber $(9.5 \%)$ & 9.8 & 10.4 & 1.1 & 4.7 & 7.6 & 0.0 \\
\hline & Roof slater \& tiler $(0.7 \%)$ & 0.7 & 1.2 & 0.0 & 0.0 & 0.9 & 0.0 \\
\hline & Steel worker (3.4\%) & 3.5 & 1.0 & 0.5 & 2.4 & 2.8 & 2.5 \\
\hline & Welder (2.9\%) & 2.9 & 1.9 & 6.4 & 7.7 & 2.6 & 0.0 \\
\hline & Unskilled workers (10.7\%) & 10.4 & 12.4 & 29.6 & 23.1 & 11.8 & 5.0 \\
\hline & Others (8.5\%) & 8.8 & 4.6 & 5.3 & 7.7 & 5.9 & 12.5 \\
\hline
\end{tabular}

Table 5 Work activity and injury severity

\section{Mechanism of Accident}

The mechanisms of accidents as shown in Table 6 were based on the Type Of Occurrences Classification System (TOOCS) of the Australian Safety and Compensation Council. Most minor and moderate injuries were related to 'struck by' incidents while serious, severe and critical were due to lifting, carrying and over-exertion. At the fatal level, besides others, the major mechanism of accident was related to equipment/vehicles (15.0\%). Electric shock and equipment/vehicle related accidents were over-represented among fatalities. While falls were under-represented among fatalities, it is one of the major causes of critical accidents $(27.6 \%)$. The outcome revealed a statistically strong association between accident mechanism and severity $\left(x^{2}=899.832\right.$, d.f. $\left.=35 ; p<0.001\right)$.

Previous studies have reported that falling from a height contributed to the most severe consequences of a construction accident (López et al. 2008; Tam et al. 2004; Huang \& Hinze 2003). In Japan, South Korea, Taiwan and Singapore, the most common type of construction deaths was due to falling from a height (Cheng et al. 2012; Im et al. 2009; Navon \& Kolton 2007). According to Cheng et al. (2012) falls are very common in private 
projects compared to public projects. Other researchers also stressed that falling from a height is the major cause of fatalities (Jackson \& Loomis, 2002; Kartam \& Bouz, 1998; Haslam et al. 2005; Navon \& Kolton, 2007; Meldrum et al. 2009; Wong et al. 2009; Larsson \& Field 2002). Arquillos (2012) found that loss of machine control and falls were higher in serious, very serious and fatal construction accidents in Spain. Poon et al. (2002) estimated that half of the construction accidents involved falling from heights and struck by objects. Struck-by accidents primarily involve workers struck by equipment, private vehicles, falling materials, vertically hoisted materials, horizontally transported materials, and trench cave-in (Hinze et al. 2005). Perttula et al. (2003) found that over-exertion was the main cause of non-fatal accidents in construction. Contact with electricity or electric discharge also emerged as a major cause of construction accidents (Wong et al. 2009). Edge protection proved to be the most sensible remedy to protect against fatal falls in the Netherlands (Ale et al. 2008). However, contrary to the popular view, falls were not very significant in the present study.

\begin{tabular}{|c|c|c|c|c|c|c|c|}
\hline \multirow{2}{*}{ Factor } & \multirow{2}{*}{ Category (\% of total accidents) } & \multicolumn{6}{|c|}{$\%$ of accidents within severity level } \\
\hline & & Minor & Moderate & Serious & Severe & Critical & Fatal \\
\hline \multirow{8}{*}{$\begin{array}{l}\text { Mechanism } \\
\text { of accident } \\
(\mathrm{N}=24,764 ; \\
\mathrm{X}^{2}=899.832 \\
\text { d.f. }=35 \\
p<0.001)\end{array}$} & Falls (19.6\%) & 18.7 & 30.8 & 20.6 & 19.5 & 27.6 & 7.3 \\
\hline & Struck by $(29.6 \%)$ & 31.2 & 41.2 & 28.0 & 16.0 & 10.8 & 10.0 \\
\hline & Caught in/between (3.0\%) & 3.0 & 7.7 & 4.2 & 5.9 & 2.0 & 5.0 \\
\hline & $\begin{array}{l}\text { Lifting, carrying, over exertion } \\
(31.9 \%)\end{array}$ & 31.0 & 6.5 & 31.7 & 42.0 & 47.2 & 2.5 \\
\hline & $\begin{array}{l}\text { Exposed to harmful substance } \\
(6.1 \%)\end{array}$ & 6.4 & 7.7 & 3.7 & 5.9 & 2.5 & 7.5 \\
\hline & Electric shock $(0.9 \%)$ & 1.0 & 1.9 & 0.5 & 0.0 & 0.2 & 7.5 \\
\hline & Equipment/vehicle (2.0\%) & 1.9 & 1.9 & 3.7 & 5.9 & 2.5 & 15.0 \\
\hline & Others $(6.8 \%)$ & 6.8 & 2.2 & 7.4 & 4.7 & 7.4 & 45.0 \\
\hline
\end{tabular}

Table 6 Mechanism of accident and severity

\section{Body Location of Injury}

Like the mechanism of accident, the body location of the injury was based on the Type Of Occurrences Classification System (TOOCS). The result shows that hand was mainly associated with minor and moderate accidents while trunk was linked with serious, severe, and critical accidents as shown in Table 7. However, the fatalities indicated a different outcome. Besides others, internal organs, multiple injuries, and head were dominant among fatalities. The results suggested a statistically significant association between the injured bodily location and severity $\left(x^{2}=1189.832 ;\right.$ d.f. $\left.=50 ; p<0.001\right)$.

\begin{tabular}{|c|c|c|c|c|c|c|c|}
\hline \multirow{2}{*}{ Factor } & \multirow{2}{*}{$\begin{array}{c}\text { Category (\% of total } \\
\text { accidents) }\end{array}$} & \multicolumn{6}{|c|}{$\%$ of accidents within severity level } \\
\hline & & Minor & Moderate & Serious & Severe & Critical & Fatal \\
\hline \multirow{11}{*}{$\begin{array}{l}\text { Injured bodily } \\
\text { location } \\
(\mathrm{N}=24,764 ; \\
\mathrm{X}^{2}=1189.832 ; \text { d.f. }= \\
50 ; p<0.001)\end{array}$} & Trunk (28.4\%) & 27.1 & 12.8 & 33.3 & 42.6 & 45.6 & 0.0 \\
\hline & Hand $(20.4 \%)$ & 21.0 & 41.2 & 18.5 & 17.8 & 9.6 & 0.0 \\
\hline & $\operatorname{Arm}(6.3 \%)$ & 6.3 & 9.4 & 4.8 & 3.6 & 7.1 & 0.0 \\
\hline & Foot $(6.7 \%)$ & 6.7 & 6.1 & 9.0 & 7.1 & 6.1 & 0.0 \\
\hline & $\operatorname{Leg}(11.9 \%)$ & 11.6 & 9.9 & 12.7 & 10.7 & 16.1 & 2.5 \\
\hline & Head $(6.8 \%)$ & 7.2 & 9.2 & 3.7 & 1.2 & 1.5 & 17.5 \\
\hline & Eye (7.6\%) & 8.4 & 1.7 & 7.4 & 1.2 & 0.4 & 0.0 \\
\hline & Neck (3.9\%) & 3.8 & 1.5 & 5.3 & 7.1 & 5.5 & 2.5 \\
\hline & Int. organs (1.4\%) & 1.4 & 3.9 & 1.6 & 3.0 & 1.2 & 27.5 \\
\hline & Multiple $(2.7 \%)$ & 2.6 & 3.9 & 2.1 & 3.6 & 3.4 & 20.0 \\
\hline & Others (3.8\%) & 3.8 & 0.5 & 1.6 & 2.4 & 3.5 & 30.0 \\
\hline
\end{tabular}

Table 7 Body location of injury and severity

Dumrak, J et al (2013) 'Factors associated with the severity of construction accidents: The Case of South Australia', Australasian Journal of Construction Economics and Building, 13 (4) 32-49 
Of all the studies cited here, Arquillos et al. (2012) is noteworthy because they discriminated between injuries that were negligible in impact to those that could lead to fatalities. The most dangerous injuries were found among concussions, to internal organs, multiple lesions, heart attack and stroke. Zhang et al. (2009) disclosed that the most commonly injured body location of US workers from 1997 to 2005 were extremities, torso, and the head and neck. Ling et al. (2009) found that in addition to multiple injuries, head and trunk were the most vulnerable areas. While the above observations are general in nature, some studies specifically focused on the relationships between a particular mechanism of accident and the injured body location (Cowley \& Leggett 2010; Kines 2002). Confirming the above results, this study showed that trunk is associated with most of the serious, severe and critical accidents while multiple locations and internal organs with fatalities.

\section{Summary of the Research Results}

The model that was originally postulated in this study (see Figure 1) to explain accident severity levels is well supported. However, the factors are re-arranged, as shown in Figure 2, in accordance with the empirical findings of the analysis of data for the South Australian construction industry. Worker characteristics, work environment and the activity undertaken by the victim decide the level of exposure that was present at the time of an accident. When that situation is triggered by an appropriate mechanism, the accident will take place. The accident coupled with the injured body location will decide the level of injury severity. While the study looked at the relationship of factors that govern the level of exposure and severity, other relationships in the model has not been explored. They are indicated by arrows WM, $\mathrm{CM}$, and WM. To obtain a comprehensive understanding of severity, these intermediate relationships need to be explored in more detail. Similarly, the intermediate relationship between mechanism and injured body location (indicated by $M L$ in Figure 2) was not covered in this study. It is proposed that these relationships could be a topic worthy of research in the future.

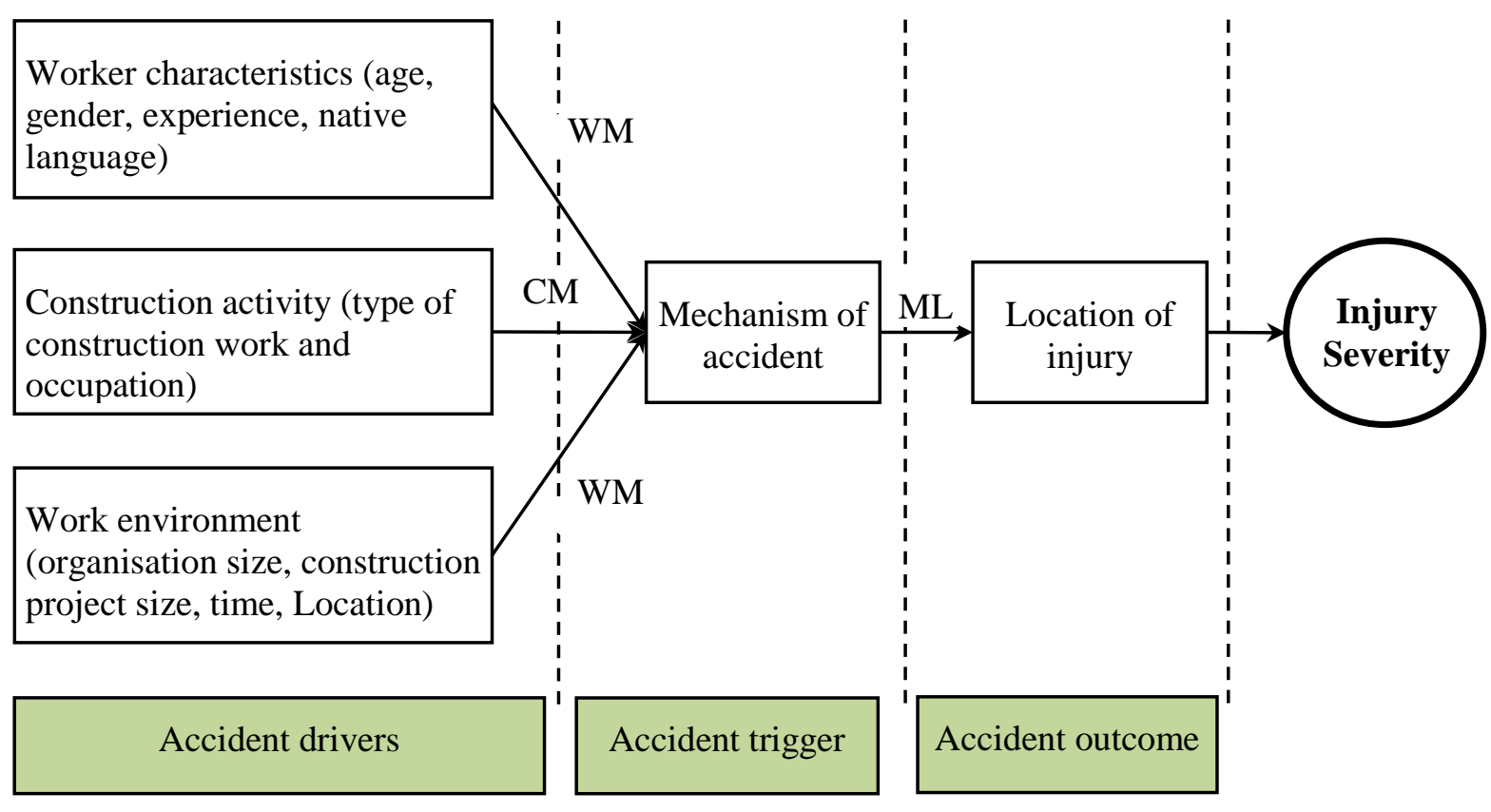

Figure 2 Conceptual model of construction injury severity

Dumrak, J et al (2013) 'Factors associated with the severity of construction accidents: The Case of South Australia', Australasian Journal of Construction Economics and Building, 13 (4) 32-49 


\section{Conclusions}

This paper presented the results of a statistical analysis carried out on 24,764 accidents reported from the South Australian construction industry during 2002 to 2011. Six severity categories and thirteen factors representing characteristics of victims, work activity undertaken at the time of accident, work environment, mechanism of accident and the injured body location were included in the study. The relationship between injury severity and those five groups of potential factors were undertaken using the chi-square independence test. The study showed that worker characteristics such as age, experience, gender and language background and work environment variables such as organisation size, project size and location, mechanism of accident, and body location of the injury could be used to discriminate among different severity levels of an accident. As the age of the worker increases the severity of accidents tends to increase. Experienced workers tend to be common among severe accidents compared to relatively new workers. Females were found to be under-represented among accidents as well as fatalities. Workers belonging to small companies and working for small projects were common among severe accidents while those from medium-sized firms and projects are the safest. Sites located in regional SA and Adelaide's outer suburbs were prone to fatal accidents compared to those in the inner suburbs. Building projects were found to be more dangerous than other types of construction, while mechanics and plant operators were common among the fatalities. Contrary to the findings from the literature, falls were not overwhelmingly related to severe accidents. Internal organs, multiple injuries and the head were mainly associated with fatal accidents compared to other body locations. While the above generalizations are not neat and clear-cut, the model seems able to explain why some accidents end up with minor severities while others prove to be fatal. Factors such as the time of accident, day of the week and the season were not strongly associated with accident severities.

Despite the valuable findings, the study suffers from a few limitations. First, the research design itself has a few shortcomings as explained in the methodology section. Studies using accident databases have these inherent weaknesses that could not be eliminated by the research design. Second, this study used percentages of accidents under each severity level. While they are useful in explaining the association between the factor and severity levels, the number does not provide any meaning unless it is converted into an 'accident rate'. To obtain accident rates, a denominator that could represent the size of the factor must be used. While we tried to obtain data related to the size of each factor (through Australian Bureau of Statistics, etc.), the large number of factors has prevented us from using accident rates for this analysis. Nevertheless, the study is useful as it is based on a very large sample that was obtained for a consecutive period of 10 years.

\section{References}

Abdelhamid, T.S. \& Everett, J.G. 2000, 'Identifying root causes of construction accidents', Journal of Construction Engineering and Management, 126 (1), 52-60

Ale, B.J.M., Bellamy, L.J., Baksteen, H., Damen, M, Goossens, L.H.J., Hale, A.R., Mud, M., Oh, J., Papazoglou, I.A. \& Whiston, J.Y. 2008, 'Accidents in the construction industry in the Netherlands: An analysis of accident reports using Storybuilder', Reliability Engineering and System Safety, 93, 1523-33

Al-Humaidi, H. \& Tan, F. 2010, 'Construction Safety in Kuwait', Journal of Performance of Constructed Facilities, 24 (1), 70-7

Aneziris, O.N., Topali, E. \& Papazoglou, I.A. 2012, 'Occupational risk of building construction', Reliability Engineering and System Safety, 105, 36-46

Ankrah, N.A., Proverbs, D. \& Debrah, Y. 2009, 'Factors influencing the culture of a construction project organisation: An empirical investigation', Engineering, Construction and Architectural Management, 16 (1), 26-47 
Arquillos, A.L., Romero, J.C.R. \& Gibb, A. 2012, 'Analysis of construction accidents in Spain, 2003-2008', Journal of Safety Research, 43, 381-8

Atkinson, A.R. \& Westall, R. 2010, 'The relationship between integrated design and construction and safety on construction projects', Construction Management and Economics, 28 (9), 1007-17

Australian Bureau of Statistics 2013, Census 2011, Australian Bureau of Statistics, Canberra, ACT

Chau, N., Gauchard, G.C., Siegfried, C., Benamghar, L., Dangelzer, J-L., Français, M., Jacquin, R., Sourdot, A., Perrin, P.P. \& Mur, J.M. 2004, 'Relationships of job, age, and life conditions with the causes and severity of occupational injuries in construction workers', International Archives of Occupational and Environmental Health, 77 (1), 60-6

Cheng, C.W., Leu, S.S., Cheng, Y.M., Wu, T.C. \& Lin, C.C. 2012, 'Applying data mining techniques to explore factors contributing to occupational injuries in Taiwan's construction industry', Accident Analysis and Prevention, 48, 214-22

Cheng, C.W., Len S.S., Lin, C.C. \& Fan, C. 2010, 'Characteristic analysis of occupational accidents at small construction enterprises', Safety Science, 48, 698-07

Chi, C., Chang, T. \& Ting, H. 2005, 'Accident patterns and prevention measures for fatal occupational falls in the construction industry', Applied Ergonomics, 36 (4), 391-00

Chi, S., Han, S. \& Kim, D.Y. 2013, 'The relationship between unsafe working conditions and workers: Behaviour and impact of working conditions on injury severity in U.S. construction industry', Journal of Construction Engineering and Management, 139 (7), 826-38

Choudhry, R.M. \& Fang, D. 2008, 'Why operatives engage in unsafe work behavior: Investigating factors on construction sites', Safety Science, 46 (4), 566-84

Cowley, S. \& Leggett, S. 2010, 'Falls from plasterers' work platforms in Australia', Journal of Health Safety and Environment, 26 (2), 259-68

Dong, X.S., Fujimoto, A., Ringen, K., Stafford, E., Platner, J.W., Gittleman, J.L. \& Wang, X. 2011, 'Injury underreporting among small establishments in the construction industry', American Journal of Industrial Medicine, 54 (5), 339-49

Fabiano, B., Currò, F. \& Pastorino, R. 2004, 'A study of the relationship between occupational injuries and firm size and type in the Italian industry', Safety Science, 42(7\&8), 587-00

Frickmann, F., Wurm, B., Jeger, V., Lehmann, B., Zimmermann, H. \& Exadaktylos, A.K. 2012, '782 consecutive construction work accidents: who is at risk? A 10-year analysis from a Swiss University hospital trauma unit', Swiss Medical Weekly, 142, 1-7

Fung, I.W.H., Tam, V.W.Y., Lo, T.Y. \& Lu, L.L.H. 2009, 'Developing a risk assessment model for construction safety', International Journal of Project Management, 28 (6), 593-00

Gangolells, M., Casals, M., Forcada, N., Roca, X. \& Fuertes, A. 2010, 'Mitigating construction safety risks using prevention through design', Journal of safety research, 41(2), 107-22.

Gibb, A., Hide, S., Haslam, R., Gyi, D., Pavitt, T., Atkinson, S. \& Duff, R. 2005, 'Construction tools and equipment - their influence on accident causality', Journal of Engineering, Design and Technology, 3 (1), 12-23

Gurcanli, G.E. \& Mungen, U. 2009, 'An occupational safety risk analysis method at construction sites using fuzzy sets', International Journal of Industrial Ergonomics, 39 (2), 371-87

Hallowell, M.R. \& Gambatese, J.A. 2009, 'Construction Safety Risk Mitigation', Journal of Construction Engineering and Management, 135 (12), 1316-23 
Haslam, R.A., Hide, S.A., Gibb, A.G.F., Gyi, D.E., Pavitt, T., Atkinson, S. \& Duff, A.R. 2005, 'Contributing factors in construction accidents', Applied Ergonomics, 36 (4), 401-15

Hinze, J. \& Wilson, G. 2000, 'Moving towards a zero injury objective', Journal of Construction Engineering and Management, 126 (5), 399-03

Hinze, J., Huang, X. \& Terry, L. 2005, 'The nature of struck-by accidents', Journal of Construction Engineering Management, 131 (2), 262-68

Huang, X. \& Hinze, J. 2003, 'Analysis of construction worker fall accidents', Journal of Construction Engineering and Management, 129 (3), 262-71

Im, H.J., Kwon, Y.J., Kim, S.G., Kim, Y.K., Ju, Y.S. \& Lee, H.P. 2009, 'The characteristics of fatal occupational injuries in Korea's construction industry, 1997-2004', Safety Science, 47 (8), 1159-62

Jackson, S.A. \& Loomis, D. 2002, 'Fatal occupational injuries in the North Carolina construction industry, 1978-1994', Applied Occupational and Environmental Hygiene, 17 (1), 27-33

Jeong, B.Y. 1998, 'Occupational deaths and injuries in the construction industry', Applied Ergonomics, 29 (5), 355-60

Kartam, N.A. \& Bouz, R.G. 1998, 'Fatalities and injuries in the Kuwaiti construction industry', Accident Analysis and Prevention, 30 (6), 805-14

Kines, P. 2002, 'Construction workers' falls through roofs: fatal versus serious injuries', Journal of Safety Research, 33 (2), 195-08

Kines, P., Spangenberg, S., \& Dyreborg, J. 2007, 'Prioritizing occupational injury prevention in the construction industry: Injury severity or absence?', Journal of Safety Research, 38, 5358

Larsson, T.J. \& Field, B. 2002, 'The distribution of occupational injury risks in the Victorian construction industry', Safety Science, 40 (5), 439-56

Li, R.Y.M. \& Poon, S.W. 2009, 'Workers' compensation for non-fatal construction accidents: review of Hong Kong court cases', Asian Social Science, 5 (11), 15-24

Liao, C.W. \& Perng, Y.H. 2008, 'Data mining for occupational injuries in the Taiwan construction industry', Safety Science, 46 (7/8), 1091-02

Ling, F.Y.Y., Liu, M. \& Woo, Y.C. 2009, 'Construction fatalities in Singapore', International Journal of Project Management, 27 (7), 717-26

Lingard, H. \& Holmes, N. 2001, 'Understandings of occupational health and safety risk control in small business construction firms: barriers to implementing technological controls', Construction Management \& Economics, 19 (2), 217-26

Lipscomb, H.J., Schoenfisch, A.L., \& Shishlov, K.S. 2010, 'Non-fatal contact injuries among workers in the construction industry treated in U.S. emergency departments', 1998-2005, Journal of Safety Research, 41, 191-95

López, M.A.C., Fontaneda, I., Alcantara, O.J.G. \& Ritzel, D.O. 2011, 'The special severity of occupational accidents in the afternoon: "The lunch effect"', Accident Analysis \& Prevention, 43 (3), 1104-16

López, M.A.C., Ritzel, D.O., Fontaneda, I. \& Alcantara, O.J.G. 2008, 'Construction industry accidents in Spain', Journal of Safety Research, 39 (5), 497-07

Loudoun, R.J. 2010, 'Injuries sustained by young males in construction during day and night work', Construction Management and Economics, 28 (12), 1313-20

Macedo, A.C. \& Silva, I.L. 2005, 'Analysis of occupational accidents in Portugal between 1992 and 2001', Safety Science, 43 (5), 269-86 
Manu, P.A., Ankrah, N.A., Proverbs, D.G. \& Suresh, S. 2012, 'Investigating the multi-causal and complex nature of the accident causal influence of construction project features', Accident Analysis and Prevention, 48,126-33

Martin, J.E., Rivas, T., Matias, J.M., Toboada, J. \& Arguelles, A. 2009, 'A Bayesian network analysis of workplace accidents caused by falls from a height', Safety Science, 47, 206-14

McVittie, D., Banikin, H. \& Brocklebank, W. 1997, 'The effects of firm size on injury frequency in construction', Safety Science, 27 (1), 19-23

Mehta, C.R. \& Patel, N.R. 2010, IBM SPSS exact tests, SPSS Inc., Cambridge, MA

Meldrum, A., Hare, B. \& Cameron, I. 2009, 'Road testing a health and safety worker engagement tool-kit in the construction industry', Engineering, Construction and Architectural Management, 16 (6), 612-32

Menzel, N.N. \& Gutierrez, A.P. 2010, 'Latino worker perceptions of construction risks', American Journal of Industrial Medicine, 53 (2), 179-87

Navon, R. \& Kolton, O. 2007, 'Algorithms for automated monitoring and control of fall hazards', Journal of Computing in Civil Engineering, 21 (1), 21-28

O'Connor, T., Loomis, D., Runyan, C., dal Santo, J.A. \& Schulman, M. 2005, 'Adequacy of health and safety training among young Latino construction workers', Journal of Occupational and Environmental Medicine, 47 (3), 272-77

Perttula, P., Merjama, J., Kiurula, M. \& Laitinen, H. 2003, 'Accidents in materials handling at construction sites', Construction Management and Economics, 21 (7), 729-36

Pinto, A., Ribeiro, R.A. \& Nunes, I.L. 2012, 'Fuzzy approach for reducing subjectivity in estimating occupational accident severity', Accident Analysis and Prevention, 45 (0-3), 28190

Poon, S.W., Wang, Y.S., Zhang, Y. \& Huang, H.Y. 2002, 'A study of construction site accident statistics', Proceedings of CIB W99 implementation of safety and health on construction sites, S Rowlinson (ed), CIB W99, May, Hong Kong, 223-27

Rameezdeen, R. \& Rathnasabapathy, S. 2007, 'The relationship between accident vulnerability and safety attitude of workers: the case of Sri Lanka', Construction Information Quarterly, 9 (2), 61-8

Rivas, T., Paz, M., Martin, J.E., Matias, J.M., Garcia, J.F., \& Toboada, J. 2011, 'Explaining and predicting workplace accidents using data-mining techniques', Reliability Engineering and System Safety, 96, 739-47

Rozenfeld, O., Sacks, R., Rosenfeld, Y. \& Baum, H. 2010, 'Construction job safety analysis', Safety Science, 48 (4), 491-8

Safe Work Australia 2013, Compendium of workers' compensation statistics Australia 201011, Safe Work Australia, Canberra, ACT

Salminen, S. 2004, 'Have young workers more injuries than older ones? An international literature review', Journal of Safety Research, 35 (5), 513-21

Salminen, S., Saari, J., Saarela, K. L. \& Rasanen, T. 1992, 'Fatal and non-fatal accidents: identical versus differential causation', Safety Science, 15 (2), 109-18

Sherratt, F., Farrell, P. and Noble, R. 2013, 'UK construction site safety: discourses of enforcement and engagement', Construction Management and Economics, 31(6), 623-35

Solís-Carcaño, R.G. \& Arcudia-Abad, C.E. 2013, 'Construction-related accidents in the Yucatan peninsula, Mexico', Journal of Performance of Constructed Facilities, 27 (2), 155-62

Tam, C.M., Zeng, S.X. \& Deng, Z.M. 2004, 'Identifying elements of poor construction safety management in China', Safety Science, 42 (7), 569-86 
Teo, E.A.L., Ling, F.Y.Y. \& Ong, D.S.Y. 2005, 'Fostering safe work behaviour in workers at construction sites, Engineering, Construction and Architectural Management, 12 (4), 410-22

Wong, F.K.W., Chan, A.P.C., Yam, M.C.H., Wong, E.Y.S., Tse, K.T.C., Yip, K.K.C. \& Cheung, E. 2009, 'Findings from a research study of construction safety in Hong Kong accidents related to fall of person from height', Journal of Engineering Design and Technology, 7 (2), 130-42

Workplace Health and Safety Queensland 2012, Construction industry report, Department of Justice and Attorney-General, Brisbane, QLD

Zhang, X., Yu, S., Wheeler, K., Kelleher, K., Stallones, L. \& Xiang, H. 2009, 'Work-related non-fatal injuries among foreign born and US born workers: Findings from the US national health interview survey, 1997-2005', American Journal of Industrial Medicine, 52 (1), 25-36 